\title{
Meigs syndrome: a case report and literature review
}

Drs Goitom Hagos (MD), Tiblese T.Michael (MD)

Orotta Medical Surgical National Referal Hospital

Wepresenta rarecase of meigs syndromeassociated with benign stromal hyperplesia of ovaries.

A 21 years old lady was referred to our chest clinic on 3-7-2007 with complaints of progressive dyspnoea, abdominal distension, weight loss and amenorrhoea of two years duration. She is single not married .She gives no history of fever or night sweats. No history of close contact with any known TB patient. Patient was on empirical treatment for liver disease and disseminated TB. Patient took two courses of anti TB medications but noted no clinical improvement. As treatment failure and poor response of treatment patient came to our chest clinic for further workup and management.

On clinical examination she was chronically sick looking, emaciated but in no form of acute respiratory distress. Had stable vital signs. She was detected to have mild pallor but not icteric and had no lymphadenopathy. Dullness with absent breath sound was observed on the ${ }^{\circledR}$ side of her chest. Cardiac findings were within normal limits. Examination of the abdomen revealed a rounded hard irregular mass $8 \times 10 \mathrm{~cm}$ size arising from the pelvic cavity. Had shifting dullness but no fluid thrill. Liver and spleen were not enlarged. Vaginal examination deferred because she was a virgin. Had normal female external genitalia. Had no leg oedema.

On Investigation: Her $\mathrm{Hb}$ was $11 \mathrm{gm} / \mathrm{dl}$, WBC $3400 / \mathrm{mm} 3$ platelet 230,000 , Urinalysis revealed no abnormality. Chest radiography demonstrated massive ${ }^{\circledR}$ sided pleural effusion. Ultrsonography examination confirmed ${ }^{\circledR}$ pleural effusion with ascites and pelvic mass on the $(\mathrm{L}) 8 \mathrm{~cm} \times 9 \mathrm{~cm}$. Paracentesis and thoracentesis from both fluids revealed transudate and no malignant cells were found .Liver, Kidney function tests and electrolytes were essentially normal.

Regardless of anti TB treatment and normal liver function and negative cytology report for malignancy the possibility of meigs syndrome was entertained. Due to poor general condition of the patient and massive ${ }^{\circledR}$ pleural effusion elective laparatomy was planed on this patient. Preoperatively pleural fluid drainge was made and applied talcum powder on the right side of the chest. Unfortunately Patients' general condition got worse with increased dyspnoea and control radiograph of the chest showed similar effusion on the $(\mathrm{L})$ side. We were forced to insert chest tube drainage on the (L) side. Patient was managed in ICU with close monitor of her oxygen saturation and vital signs. She was also on continuous cardiac monitor. As the general condition of the patient improved she went for exploratory laparatomy on $01-02-08$ under epidural anaesthesia.

Intraoperatively solid ovarian tumour about $12 \mathrm{~cm}$ in diameter was found on the (L) adenexia adherent to the left lateral pelvic wall. There was no palpable pelvic nor par aortic lymph node enlargement .No abnormality was detected in liver, spleen, kidneys omentum and intestines. Intra operatively adhesion was released and $(\mathrm{L})$ unilateral salpingo-oophorectomy was performed on the patient. There was about $400 \mathrm{ml}$ of straw coloured ascetic fluid found in the peritoneal cavity. Patient was followed in ICU, and her post operative course was uneventful. On the 4th post operative day chest examination revealed good air entry on both lung fields and no signs of fluid was detected on physical examination. Control radiography done on the 9 th post operative day showed pleural thickening with normal lungs and no signs of pleural effusion. Both drainge tubes were removed and patient was quiet stable with no complaints related to respiratory symptoms. The surgical wound healed well and patient was discharged home on 14-01-2008 after thirteen post operative day in stable general condition. Subsequently patient was on follow up and control radiography done six months after her discharge revealed, normal lungs and heart with no signs of pleural effusion. She is quite comfortable and gained some weight.

\section{Pathology:}

The specimen consists of (L) mesovarium well encapsulated firm tumour measuring $10 \times 11 \times 8$ centimetres. Pathologic study of the tumour confirmed the absence of malignancy. The study also identified the tumour as ovarian fibroma.

\section{Discussion:}

Meigs syndrome is defined as the triad of benign ovarian tumour with ascites and pleural effusion that resolves after resection of the tumour. The ovarian tumour in Meigs syndrome is a fibroma.

Meigs J.V in 1937 described a syndrome comprising of a fibroma of the ovary with ascites and hydrothorax in a report of 7 cases. This syndrome has been named after him and must fulfil the minimal criteria of pleural effusion, solid ovarian tumour and clearing of effusion after removal of the tumour. Pelvic tumours other than solid tumours which fulfil the other criteria have been termed as pseudo-Meigs syndrome.

The incidence of ovarian fibroma is $2-5 \%$ of all surgically removed ovarian tumours and, Meigs syndrome is observed in about $1 \%$ of the cases. Ascites is present in $10-15 \%$ and hydrothorax in $1 \%$, especially with larger lesions .Although Meigs syndrome mimics a malignant condition, it is benign disease and has a very good prognosis if properly managed. Life expectancy after surgical removal of the tumour is similar to the healthy general population .Meigs 
syndrome in prepubertal girls with benign teratomas and cystadenomas has also been reported.

There are many mechanisms postulated as to the presence of pleural effusion and ascites in Meigs syndrome. The mechanisms reported were actual secretion by tumor or peritoneum, venous obstruction, Lymphatic obstruction, low serum protein, toxins and inflammatory reaction with exudates.

As far as we know, this is the first documented case in Eritrea .In our patient the fact that the pleural effusion resolved completely with out recurrence after operation confirms the diagnosis of Meigs syndrome. Though a rare entity, one can encounter such cases in clinical practice, and this case emphasise a histopathologic diagnosis is a must when there is a diagnostic dilemma.

\section{Chest radiography showing a right pleural effusion}

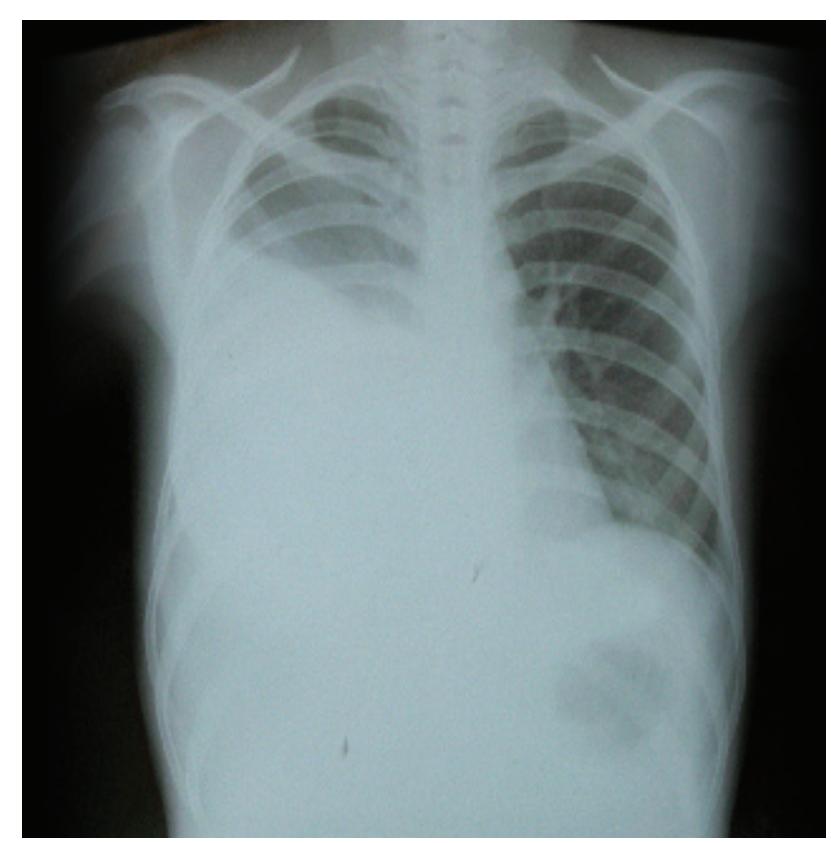

Chest radiography pre operatively with chest tube in place And bilateral effusion after talcum powder application

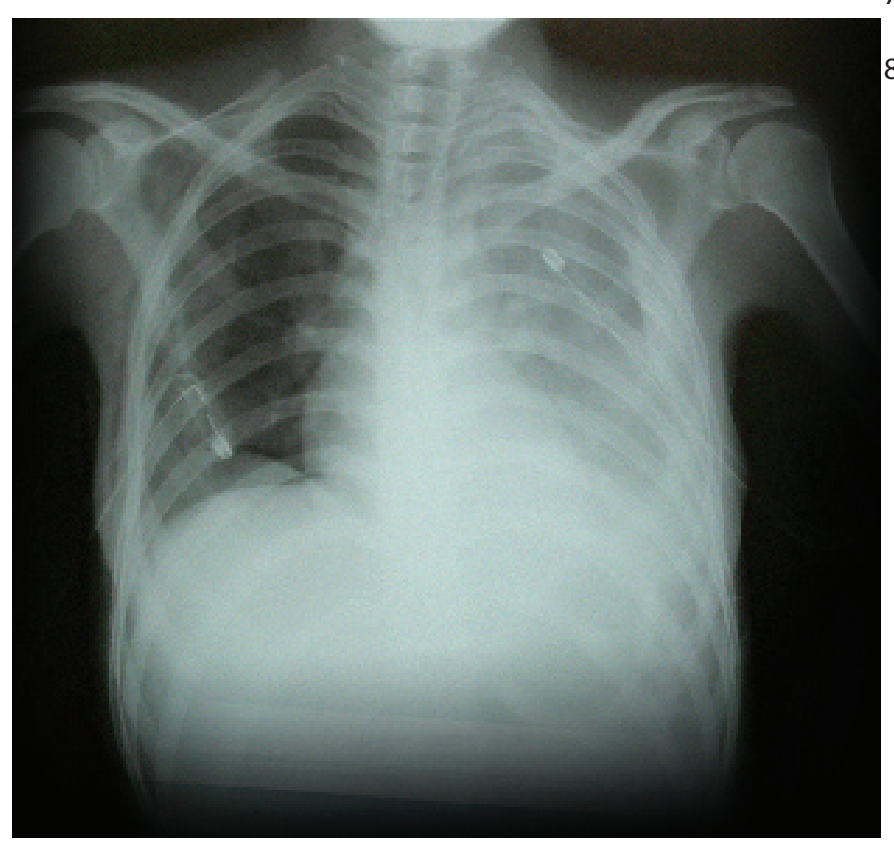

Same patient resolving pleural effusion on the 9th post operative day

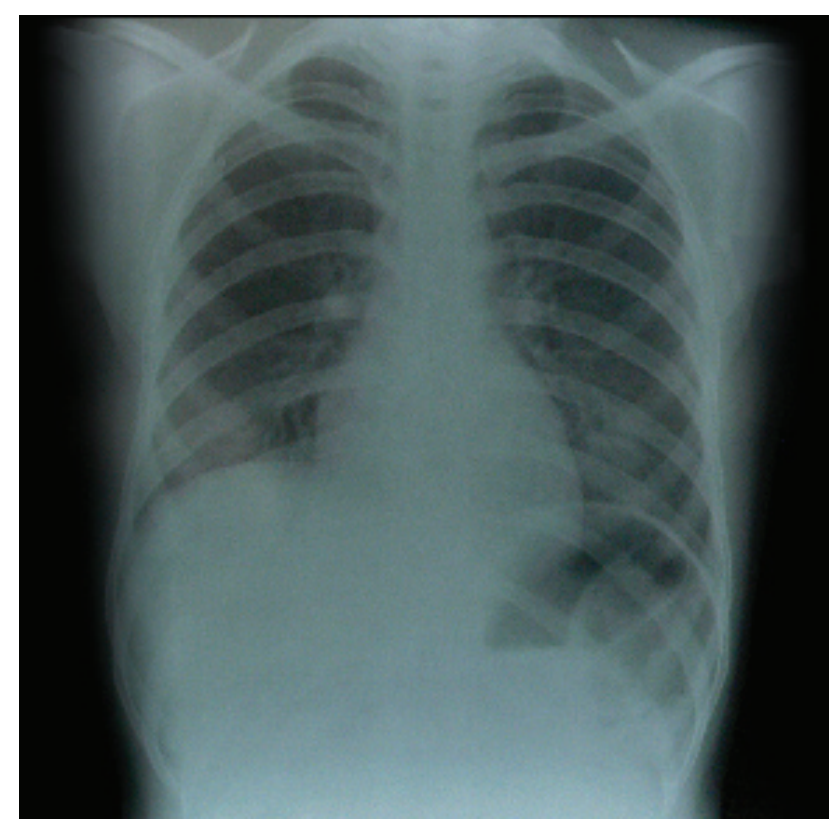

\section{ACKNOWLEDGEMENT}

We wish to express our gratitude to all who were involved directly or indirectly in the care and management of our case. Special thanks and appreciation goes to all our ICU staff that showed great devotion and high standard care on our patient.

\section{REFERENCES}

1. Meigs syndrome: clinical picture and treatment Ann Ital Chir 2000; 71:115

2. Meigs syndrome: Is it possible to make pre operative diagnosis? J Gynecol obstet1998; 27:517-22.

3. Pseudo-Meigs syndrome. Am J Emerg Med 1998; 16 (4):389-90

4. Pseudo meig syndrome caused by Para ovarian fibroma. Eur J Gynecolo oncol 1998; 19(4):389-90

5. Meigs syndrome case report. Eur J Gynaecolo oncol 2004; 25: 528-9

6. pseudo-Meigs syndrome and elevated serum CA 125. Gynecol oncol

7. Atypical cystadenofibroma with Meigs syndrome .Cancer. 1982; 49(3):472

8. Fibroma of ovary with ascites, hydrothorax: seven case reports. Am J obstet Gynecol. 1937; 33:249 